\title{
Da política pública de educação do campo à prática acadêmica para a formação de professores
}

\author{
From the public policy of countryside education to the academic practice for teacher training \\ De la politique publique de l'éducation paysanne à la pratique académique pour la formation des \\ enseignants
}

Luiz Henrique Magnani ${ }^{1}$

Universidade Federal dos Vales do Jequitinhonha e Mucuri

Carlos Henrique Silva de Castro ${ }^{2}$

Universidade Federal dos Vales do Jequitinhonha e Mucuri

Luiz Otávio Costa Marques ${ }^{3}$

Universidade Federal dos Vales do Jequitinhonha e Mucuri

Resumo: Este artigo discute aspectos da proposta teórico-metodológica da área de línguas da Licenciatura em Educação do Campo da Universidade Federal dos Vales do Jequitinhonha e Mucuri - UFVJM, com o intuito de contribuir com a reflexão sobre a realidade da implementação, consolidação e manutenção dessa política pública no ensino superior brasileiro. A graduação, instituída em 2013, objetiva formar professores com habilitação em Ciências da Natureza ou Linguagens e Códigos para lecionar nos anos finais do ensino fundamental e no ensino médio de escolas do meio rural. A proposta em pauta resulta de um diálogo entre os pressupostos teóricos da Educação do Campo, que reconfiguram o ensino em escolas que atendem às populações campesinas; da linguística aplicada (LA), de perspectiva interdisciplinar; e de estudos de letramentos, que reconhecem e problematizam os novos usos da linguagem.

Palavras-chave: Políticas públicas. Formação de professores. Educação do Campo. Linguística Aplicada. Letramentos.

Abstract: This article discusses aspects of the theoretical and methodological proposal of the language area of the undergraduate course in Countryside Education from the Federal University of the Jequitinhonha and Mucuri Valleys - UFVJM, with the purpose of contributing to the reflection on the reality of the implementation, consolidation and maintenance of this public policy in Brazilian higher education. The course, which was instituted in 2013, aims to train teachers in the areas of Natural Sciences or Languages and Codes to work in the final years of elementary education and in high school in rural areas. The proposal in question results from a dialogue between the theoretical presuppositions of

\footnotetext{
1 Doutor em Letras (USP). Professor do Curso de Licenciatura em Educação do Campo/UFVJM. henriquemagnani@gmail.com.

${ }^{2}$ Doutor em Linguística Aplicada (Linguagem e tecnologia) (UFMG). Professor do Curso de Licenciatura em Educação do Campo/UFVJM. ccastrobr@gmail.comProf.

${ }^{3}$ Mestre e doutorando em Estudos Linguísticos e Literários em Inglês (USP). Professor do Curso de Licenciatura em Educação do Campo/UFVJM. luizocmarques@gmail.com.
} 
Countryside Education, which reconfigure the teaching in schools that attend rural populations; of applied linguistics (LA) from an interdisciplinary perspective; and of literacy studies, which recognize and problematize the new uses of language.

Keywords: Public policies. Teacher Education. Countryside Education. Applied Linguistics. Literacy.

Résumé: Cet article examine aspects de la proposition théorique et méthodologique du domaine des langues du cours supérieur en éducation paysanne de l'Université Fédérale des Vallées de Jequitinhonha et de Mucuri - UFVJM, avec l'intention de contribuer à la réflexion sur la réalité de la implémentation, la consolidation et le maintien de cette politique publique dans l'enseignement supérieur brésilien. Le cours, institué en 2013, vise à former des enseignants en sciences naturelles ou langages et codes pour enseigner dans les dernières années de l'école primaire et dans l'école secondaire en zones rurales. La proposition en question résulte d'un dialogue entre les présupposés théoriques de l'éducation paysanne, qui reconfigurent l'enseignement dans les écoles au service des populations paysannes; de la linguistique appliquée (LA) dans une perspective interdisciplinaire; et des études récentes d'alphabétisation, qui reconnaissent et problématisent les nouveaux usages du langage.

Mots-clés: Politiques Publiques. Formation des Enseignants. Education Paysanne. Linguistique Appliquée. Alphabétisation.

\section{A Institucionalização da Licenciatura em Educação do Campo na UFVJM enquanto Política Pública Nacional}

Conforme sintetiza Lima (2012), a população do campo teve, historicamente, uma relação precária ou inexistente com a educação formal, mesmo no período em que o país era majoritariamente agrário. Como resposta recente a essa realidade, emerge a Educação do Campo, propulsionada pelas lutas do fim do século $\mathrm{XX}$ - protagonizadas por movimentos sociais do campo e sindicatos rurais - em prol de uma política educacional para comunidades do campo e de reforma agrária. Essa mudança tem intensificado, consideravelmente, o interesse e a produção de pesquisas na área, fortalecendo um olhar para o campo mais condizente com os saberes e as expectativas locais.

Um dos marcos da Educação do Campo no Brasil se dá com a I Conferência Nacional Por Uma Educação Básica do Campo, realizada em 1998 em Luziânia-GO. Segundo Andrade (2009), a Conferência, 
para além de ser um momento de denúncia da precária situação da educação do campo em todo o país, ela se configurou em um espaço de reafirmação dos princípios que conferem identidade ao campo e da legitimidade da luta por políticas públicas específicas, formuladas com a participação dos sujeitos do campo. [...]. Essa conferência foi, de certa forma, uma resposta à falta de políticas públicas implementadas pelo Estado, o qual tratava a educação do campo como educação rural, com concepções ideológicas advindas do mundo urbano e sem nenhuma utilidade aos interesses dos sujeitos do campo, por isso deu origem a um grupo permanente de debate e de proposição: a Articulação Nacional Por Uma Educação do Campo, integrada por representantes do MST, CNBB, UnB, UNESCO e UNICEF, com a finalidade de continuar o movimento iniciado (p.59-60).

A articulação em questão vem viabilizando fóruns, encontros e produzindo registros que, aos poucos, vão consolidando a área da Educação do Campo em contraste a uma educação rural que tendia a partir de "uma concepção preconceituosa a respeito do camponês", por não considerar "os saberes decorrentes do trabalho dos agricultores" (RIBEIRO, 2012, p. 298). Dentre esses registros, destaca-se a "Declaração - 2002", na qual o grupo contextualiza sua existência e um pouco de seus pressupostos:

[n]ossa caminhada enquanto articulação nacional Por uma Educação do
Campo começou no processo de preparação da Conferência Nacional Por uma
Educação Básica do Campo, realizada em Luziânia, Goiás, de 27 a 31 de julho
de 1998. A ideia da Conferência, por sua vez, surgiu durante o I Encontro
Nacional de Educadoras e Educadores da Reforma Agrária (I ENERA) feito
em julho de 1997. A Conferência, promovida a nível nacional pelo MST, pelo
CNBB, UnB, UNESCO, e pelo UNICEF, foi preparada nos estados através
de encontros que reuniram os principais sujeitos de práticas e de
preocupações relacionadas à educação do campo. Na Conferência
reafirmamos que o campo existe e que é legítima a luta por políticas públicas
específicas e por um projeto educativo próprio para quem vive nele [...]
(SEMINÁRIO NACIONAL POR UMA EDUCAÇÃO DO CAMPO, 2002,
p. 11).

Nota-se, portanto, um processo nacional em curso, no qual as políticas públicas e o projeto de Educação do Campo ganham forças a partir de uma articulação entre acadêmicos, educadores, movimentos sociais e sindicatos rurais. Uma das principais conquistas desse grupo foi a instauração de Licenciaturas em Educação do Campo em universidades públicas das diversas regiões do país. Esse processo se torna possível a partir da criação do Programa de Apoio à Graduação em Educação do Campo (Procampo), política pública vinculada ao Ministério da Educação (MEC), voltada à formação de professores para atuar nos anos finais do ensino fundamental e no ensino médio nas escolas rurais. Em particular, a Universidade Federal dos Vales do Jequitinhonha e Mucuri (UFVJM), com campi nas regiões norte, nordeste 
e noroeste do estado de Minas Gerais, foi uma das instituições que passou a oferecer o curso e, com isso, parte de sua comunidade acadêmica tem vivenciado muitos desafios em sua rotina para o processo de implementação e consolidação dessa graduação.

No caminho dessa luta, ao fim do citado Procampo, que contou com uma única turma em caráter experimental, abre-se espaço para a institucionalização de uma licenciatura em diálogo com as demandas de uma educação voltada para os sujeitos do campo. A universidade concorreu, assim, ao Edital SESU/SETEC/SECADI n 2/2012 para ofertar, de modo permanente, o curso Licenciatura em Educação do Campo (LEC). Com a aprovação do projeto, a primeira turma da LEC - UFVJM iniciou-se ao fim de 2013. De acordo com o Projeto Pedagógico do Curso (PPC):

com a publicação do Edital n ${ }^{\circ}$ 02, SESU/SETEC/SECADI/MEC, de 31 de agosto de 2012, a UFVJM submeteu novo Projeto Político Pedagógico para Graduação em Educação do Campo, obtendo aprovação por meio da Portaria n 72 , MEC, de 21 de dezembro de 2012. O curso de Graduação em Educação do Campo da UFVJM/Licenciatura passou a chamar-se Licenciatura em Educação do Campo - LEC (UFVJM, 2018, p. 6).

Desde então, o curso, que habilita professores para atuar nos anos finais do ensino fundamental e no ensino médio em uma entre duas áreas de conhecimento - Linguagens e Códigos ou Ciências da Natureza - permanece ativo e em constante renovação. É a partir desse cenário que trazemos nossas reflexões. A fim de elucidar o leitor, estes autores são professores da referida licenciatura, mais especificamente da habilitação Linguagens e Códigos, e os fatos que sustentam nossa argumentação são oriundos de nossas observações de cunho qualitativo, bem como de dados oriundos de documentos públicos, devidamente referenciados e facilmente acessíveis, além da discussão de nossa realidade em reuniões com todos os docentes da área que acontecem mensalmente e do nosso grupo de pesquisa, ainda a ser apresentado, que acontecem na mesma periodicidade.

O exemplo da UFVJM não é um caso isolado, mas se insere em uma política pública de abrangência nacional. A respeito dos processos que levaram a essa institucionalização da Educação do Campo como formação docente de nível superior, Molina e Antunes-Rocha (2014) ressaltam que:

a criação dessa nova modalidade de Licenciatura, a qual se estrutura em instituições de ensino superior no Brasil a partir de 2007, é resultado da luta dos movimentos sociais e sindicais que depois de dez anos de luta, finalmente, conquistam uma política de formação inicial para educadores do campo, 
vinculada, pela primeira vez, ao Ministério da Educação, a partir da criação do Programa de Apoio à Formação Superior em Licenciatura em Educação do Campo- Procampo [...]. Consideramos importante ressaltar que esta história da construção de políticas de formação de educadores do campo se forja eivada de desafios e tensões, que se expressam não só nos inúmeros problemas enfrentados nas escolas do campo onde estes educadores em formação atuam, mas também na própria oferta dos cursos, que, de maneira geral, em todos estes anos do Pronera, desenvolveram-se com dificuldades de várias ordens. Dificuldades na relação com as próprias universidades ofertantes dos cursos, que, muitas vezes, apresentam forte resistência às matrizes formativas propostas pelos movimentos camponeses: o trabalho; a luta social; a organização coletiva; a cultura e a história. A construção do perfil do educador do campo, a partir destas matrizes formadoras vai se forjando, na maior parte das experiências, à revelia das instituições, ensinando às próprias universidades, uma nova concepção de formar educadores, a partir da ocupação, pelos sujeitos coletivos do campo, dos espaços acadêmicos (2014, p. 236, grifo nosso).

A parte final do excerto citado, em destaque, tem foco na tensão entre um certo projeto de Educação do Campo, que vai se formando a partir de olhares e expectativas de acadêmicos e movimentos sociais, muitas vezes dissonantes, e os conflitos inerentes à institucionalização de uma proposta de educação claramente contra-hegemônica que entra em atrito com a lógica epistemológica já consagrada da academia. De todas essas tensões, podem resultar as mais diversas situações, como, por exemplo, algumas empiricamente trazidas pela rotina desses anos iniciais de implementação da LEC na UFVJM e que serão mencionadas nas próximas seções.

Para a construção deste artigo, destacou-se, entre esses elementos, o processo de redirecionamento teórico de um grupo de disciplinas da área de Linguagens e Códigos resultante da atualização do projeto pedagógico do curso, assim como algumas práticas pedagógicas já executadas ou em realização que buscam se alinhar com demandas concretas da formação de docentes no contexto da Educação do Campo. Entende-se que, tanto analisar aspectos da revisão teórica e epistemológica em curso na LEC-UFVJM, como também apresentar alguns percursos já trilhados, pode ajudar na compreensão mais ampla sobre esse local em construção previsto na Educação do Campo e, mais especificamente, na habilitação em Linguagens e Códigos.

Uma vez feita essa breve contextualização, as próximas seções dedicam-se a explicitar aspectos do percurso de implementação da graduação em questão e o direcionamento teórico de um grupo de disciplinas da área de Linguagens e Códigos da LEC-UFVJM, com o intuito de, a partir de um exemplo empírico, contribuir com a reflexão sobre a realidade da 
implementação, consolidação e manutenção dessa política pública no ensino superior brasileiro.

\section{Da Política Pública de Educação do Campo à Prática Acadêmica na LEC-UFVJM}

O percurso de implementação, atualização e manutenção do curso em foco está permeado de dificuldades, contradições, ajustes, algo que é típico de qualquer processo de construção de uma política pública de abrangência nacional. É ilustrativo da particularidade desse quadro o fato de que o corpo docente da LEC/UFVJM não tenha, atualmente, nenhum dos pesquisadores com formação superior especificamente na área de Educação do Campo. É esperado que isso ocorra - sendo uma área recente ainda hoje, e era mais ainda na ocasião dos concursos públicos efetuados para o preenchimento de vagas de professores. Além disso, ainda são quase inexistentes no Brasil as pós-graduações na área. Assim, visando superar essa lacuna em sua formação acadêmica, os professores da LEC-UFVJM, além de participar em eventos acadêmicos sobre Educação do Campo, colaboram ativamente na gestão pedagógica do curso, reunindo-se sistematicamente para discutir e revisar o seu projeto pedagógico, o qual se encontra em sua terceira versão; planejar, avaliar e redefinir as ações pedagógicas previstas e, mais recentemente, discutir textos teóricos sobre Educação do Campo em grupo de estudo. No que tange à falta de vivência desses professores formadores em comunidades campesinas, a participação constante em atividades didático-pedagógicas realizadas com o apoio do corpo discente e de representantes de movimentos sociais no meio rural possibilita a esses docentes ressignificar suas práticas pedagógicas e o seu papel enquanto professores formadores de educadores do campo.

A intensidade dessa rotina de práticas dos docentes pode ser estimada pelo fato de a publicação da terceira revisão do projeto pedagógico ocorrer no mesmo semestre em que o curso forma sua primeira turma, ou seja, no primeiro semestre de 2018. É de se ressaltar, a esse respeito, que a maioria dos docentes do curso ingressou na instituição depois da primeira versão do projeto e que, muitos deles, em especial da área de Estudos Linguísticos, ingressaram somente depois de sua segunda versão. Portanto, para a efetivação do projeto naquele primeiro momento, contou-se com a ajuda maciça de professores e voluntários externos ao curso. Considerando que muitos desses colaboradores eram atuantes em cursos de Letras, não é de se estranhar que grande parte das primeiras ementas pensadas e desenvolvidas para disciplinas específicas de ensino de língua e estudos linguísticos, por exemplo, seguiam a estrutura disciplinar e a lógica de funcionamento da chamada Linguística Moderna. 
Embora esperada, é uma situação que não deixa de gerar algumas tensões e contradições. A hegemonia do pensamento e da lógica de organização da Linguística Moderna - e em especial de tendências estruturalistas e gerativistas dentro dessa linguística - incidia, por exemplo, no próprio modo de pensar o quadro de unidades curriculares de estudos linguísticos, próprio da habilitação em Linguagens e Códigos. A esse respeito, é possível trazer algumas considerações.

Unidades curriculares de 60 horas cada coincidiam com as unidades de análise privilegiadas nessa linguística mais formal e geravam as seguintes disciplinas: Fonética e Fonologia da Língua Portuguesa, Morfologia da Língua Portuguesa, Sintaxe da Língua Portuguesa. "Semântica e Pragmática", outra unidade curricular de 60 horas, traz componentes da linguagem que a despeito de não serem necessariamente os mais privilegiados pelo 'núcleo duro' da linguística, são objetos consolidados no estudo da área. Mais que isso, seguem a mesma lógica estrutural de que a língua pode ser analisada em níveis de análise que vão de unidades menores (como seria o exemplo da Fonologia) a maiores. A todas essas unidades curriculares, somava-se "Introdução aos Estudos Linguísticos”, também de 60h, cuja ementa priorizava explicitamente questões da "linguística de Saussure" e da "Teoria Gerativa" (UFVJM, 2014). Mesmo sendo difícil mensurar o que isso significa quantitativamente, vale pontuar que essa carga corresponde a quase metade das disciplinas ligadas aos estudos linguísticos, ou, mais precisamente, a $300 \mathrm{~h}$ de $675 \mathrm{~h}$.

Dentre as demais disciplinas vinculadas à área de estudos linguísticos, a lógica permanecia a de priorizar unidades curriculares focadas em limites disciplinares, privilegiando áreas que surgiram, em um geral, em resposta a essa linguística hegemônica. São exemplos disso as unidades curriculares de Linguística Textual, Sociolinguística, Análise do Discurso e Linguística Aplicada ao Ensino de Língua Portuguesa, cada qual também com 60h. Vale ressaltar que a própria denominação da disciplina de Linguística Aplicada reiterava a visão de que essa área de conhecimento seria uma aplicação, em contextos de ensino, do que era próprio da linguística teórica. Eram exceções as unidades curriculares focadas em objetos mais amplos e contextualizados, tais como "Gêneros Discursivos e Textuais" (45h) e "Linguagens e Códigos: Ensino e Novas Tecnologias" (30h). A unidade curricular "Metodologias de Ensino de Língua Portuguesa”, com 60h, completa a matriz curricular do antigo PPP vinculada à área de estudos linguísticos. Junto a isso, a habilitação de Linguagens e Códigos possui um conjunto de disciplinas de literatura e outro de língua estrangeira, para além das unidades curriculares 
vinculadas às ciências humanas oferecidas em comum com a habilitação em Ciências da Natureza.

Procura-se explicitar, por meio dessa explanação bastante sumarizada, que a influência de certo modo de pensar o estudo e o ensino de língua e linguagem, mais vinculada a visões hegemônicas da Linguística Moderna, eram visíveis não apenas no conteúdo trabalhado, mas também na forma de se pensar e organizar as unidades curriculares o que seria pertinente à área dos estudos linguísticos. Essa configuração dificultava, por exemplo, diálogos entre as unidades curriculares e outras tentativas de trabalhar o saber de modo menos fragmentado.

É também exemplo dessas tensões próprias desse início de caminhada o fato de que, desde sua versão anterior de 2014 (UFVJM, 2014), o PPC do curso prevê uma estrutura multi, inter e transdisciplinar de curso, atividades contextualizadas e um diálogo com a pedagogia da autonomia (FREIRE, 2003)4. Porém, os docentes, agentes sociais com poder e responsabilidade de efetivar boa parte desses anseios, foram eles próprios formados em uma estrutura disciplinar, centrada no saber científico de modo mais abstrato e sem vivências com comunidades para além do restrito círculo acadêmico. Essas e outras situações não previstas na formação de tais professores são vivenciadas pela comunidade acadêmica vinculada ao curso e, normalmente em tempo reduzido, exigem respostas, reflexões, estudos, propostas desses docentes e de servidores técnicos e estudantes - todos, na prática, igualmente em um processo de aprendizado a respeito de metodologias e epistemologias que norteiam a Educação do Campo.

Dentro do que foi exposto, entende-se que um olhar da Linguística Aplicada (LA) e estudos recentes de letramentos podem ser particularmente benéficos para um viés acadêmico da Educação no Campo na área de Linguagens. Em linhas gerais, na literatura recente da área, uma visão específica de LA tem ganhado força dentre os teóricos da comunidade científica. Essa visão desconstrói um olhar historicamente atribuído à LA como área secundária a pensar na aplicação prática das teorias elaboradas pelos linguistas (SIGNORINI, 1998; FABRÍCIO, 2006; MOITA LOPES, 2006; 2009). Em contrapartida, essa visão anuncia um rompimento com o próprio fazer ciência historicamente consagrado na Linguística Moderna, bem como com suas visões de linguagem.

\footnotetext{
${ }^{4}$ Conforme o PPC (UFVJM, 2018, p. 21), enquanto a disciplinaridade promove um saber fragmentado, a interdisciplinaridade objetiva promover o diálogo entre as várias disciplinas, contribuindo “[ [...] para a construção de um conhecimento que inclua a diversidade e a coletividade”. A multidisciplinaridade, por sua vez, “[ [...] joga sobre o mesmo objeto olhares das diferentes disciplinas". Já a transdisciplinaridade “[ [...] preconiza o fim das fronteiras entre as disciplinas, sendo definida como um novo modo de produção de conhecimento”.
} 
Signorini (1998) contrapõe esses dois olhares. Conforme a autora, a LA atual se oporia a um conceito "genérico abstrato e único de língua" herdado da tradição científica da modernidade, priorizando um olhar "múltiplo não unificado, produzido por percursos transdisciplinares de reflexão" (SIGNORINI, 1998, p.102). No primeiro caso, coloca-se foco no "sistema genérico de leis e propriedades, construído para descrever a língua em questão"; já a segunda visão se volta para regularidades percebidas localmente e para uma dinâmica de "relações moventes [...] no(s) modo(s) de funcionamento do linguístico em condições dadas de uso", o que permite olhar para o que a autora pontua como "língua real”, uma língua possível de ser objeto de investigação acadêmica, porém sem "arrancar o objeto da tessitura de suas raízes” (SIGNORINI, 1998, p. 103). Para a autora, o deslocamento realizado pela LA tem como principal implicação epistemológica:

[...] o rompimento com cadeias conceituais e expectativas teleológicas e totalizantes, em favor de uma sistematicidade tão rigorosa - ou tão 'científica' - quanto possível, mas aberta e orientada para o acontecimento[...] (SIGNORINI, 1998, p. 103).

Em particular, pode-se dizer que o desafio apresentado com a implementação de uma habilitação de Linguagens e Códigos em um curso de Licenciatura em Educação do Campo que prevê posturas epistemológicas e metodológicas conflitantes com o perfil hegemônico das graduações no Brasil - pode-se beneficiar de um olhar cuja sistematicidade é voltada "para o acontecimento", como proposto por Signorini (1998). Ao se entender que essa situação concreta pode se beneficiar das contribuições metodológicas e epistemológicas oferecidas pela literatura contemporânea da LA, argumenta-se haver uma fecunda possibilidade de alinhamento entre a área em questão e demandas atuais da Educação do Campo.

Retomando, a título de ilustração, o caso empírico da LEC-UFVJM, olhar para a Educação do Campo, a partir da perspectiva da LA, permite e estimula, por exemplo, uma proposta investigativa que esteja em linha com as ideias de multi, inter e transdisciplinaridade, conforme espera o projeto pedagógico do curso desde sua versão inicial. Mais que isso, pensando na política pública nacional de Educação do Campo, seu aporte teórico e suas demandas, tal articulação se mostra propícia pela comum sensibilidade em relação a problemas sociais concretos e por uma vocação para a transformação social, características explicitamente constituintes da Linguística Aplicada (EVENSEN, 1998; SIGNORINI, 1998).

Desse modo, o caminho de articulação proposto auxiliaria a pensar e trabalhar questões práticas e teóricas geradas pela institucionalização da Educação do Campo enquanto licenciatura e, mais especificamente, da habilitação na área de Linguagens e Códigos. De um 
lado, é possível conceber que tal área, até por denominação, tem nas linguagens seu objeto de estudo central. Desse modo, a academia de fato tem um longo acúmulo de estudos, nas mais diversas disciplinas, que podem contribuir em sua constituição. Porém, e aí reside o desafio e a particularidade, o olhar sobre o objeto parte de um olhar epistemológico e metodológico que também possui um percurso específico, que é o da Educação do Campo. Ou seja, é um olhar que deve dialogar com as discussões de uma educação que se quer popular, a partir da necessidade de contextualização, do respeito a identidades e diferenças, do desenvolvimento de autonomia, entre outros pressupostos.

É necessário ponderar que todas essas questões, no entanto, costumam ser bastante invisibilizadas pela tradição da Linguística Moderna e, até mesmo, por um processo acadêmico mais amplo, que lida com as práticas letradas existentes e historicamente construídas como se fossem naturais, universais ou transparentes. Gera-se, com isso, uma espécie de apagamento do fato de que a própria universidade também faz parte de uma lógica de trocas linguísticas e simbólicas mais ampla, a qual, para usarmos o termo de Bourdieu (1996), opera como um 'mercado de trocas linguísticas'. Dentro desse mercado, a instituição universitária avalia, certifica, desqualifica, altera, valoriza, apropria-se não só de visões sobre a linguagem, mas também de práticas e usos de linguagem, dentre as quais, destacam-se a leitura e a escrita. Ou, mais especificamente, certos padrões de leitura e escrita, historicamente definidos e consolidados como mais adequados às exigências de uma certa cientificidade.

A esse respeito, é necessário inclusive levar em consideração que o próprio domínio da Educação do Campo é heterogêneo, construído a partir de uma fundamentação teórica multidisciplinar e envolve áreas que historicamente possuem percursos teóricos muitas vezes distintos e não necessariamente conciliáveis. A Educação do Campo, enquanto área, envolve tanto reflexões mais gerais a respeito do direito à educação e da realidade campesina provindas de áreas como sociologia ou direito, bem como desafios específicos de cada habilitação, podendo abarcar, em cada universidade na qual o curso foi efetivamente implementado, uma gama de tradições científicas que vão desde a Física e Química até a Educação Artística e os Estudos Literários.

Dentro dessa heterogeneidade, não necessariamente os pressupostos que são trazidos das diversas áreas possuem uma conceituação clara a respeito das práticas de leitura e escrita, sejam as acadêmicas, escolares ou, mais amplamente, comunitárias. Essas questões, ao não serem objeto de estudo específico de outras áreas, correm o risco de serem tomadas como naturais ou transparentes. Nesse sentido, assim como também ocorre em outros contextos 
ligados à educação e à academia ${ }^{5}$, é possível encontrar nos discursos públicos sobre formação de professores para o Campo - ainda que nem sempre de modo explícito ou fundamentado teoricamente com estudos do letramento - vertentes, práticas e sujeitos alinhados com concepções dominantes de letramento, tal como a ideia do "letramento autônomo" (STREET, 2014) e sua crença subsequente em uma relação direta entre aperfeiçoamento pessoal ou cognitivo e domínio de certa escrita. E, nesse sentido, deve-se atentar para que a particularidade da academia e do discurso teórico enquanto prática letrada não se oponha à proposta de resgatar, respeitar e articular saberes locais com os conhecimentos legitimados em nível global.

Esse tipo de situação, no entanto, também é objeto de reflexão teórica - em especial em algumas correntes de estudos sobre letramento. Para Street (2014), apesar de a escrita e o letramento, em uma visão dominante atual nas sociedades ocidentais, estarem estritamente associadas com a prática escolar, essa relação não é óbvia nem direta, apenas contingencial. Além disso, o autor mostra que ao priorizar o padrão de texto dissertativo-científico como modelo de correção, concepções dominantes de letramento não dão conta de abarcar ou pressupor a variedade de práticas letradas outras existentes em uma sociedade. Nesse sentido, pode-se considerar, aliás, que a academia constantemente reforça um padrão de escrita específico e o pressupõe como o ponto de partida mínimo de um graduando. Além disso, tende a avaliar o estudante primordialmente a partir do seu desempenho nessas práticas letradas dominantes.

Assim, vê-se que a "monocultura do saber acadêmico" (SANTOS et al., 2005) - mantida e propagada pelo pensamento científico dominante - é também viabilizada por essa espécie de “monocultura do letramento acadêmico". Esse processo, ao legitimar um feixe muito restrito de gêneros discursivos como práticas válidas de escrita ou de expressão pública, pode entrar em conflito com um dos pilares da Educação do Campo, que é um entendimento mais aprofundado do papel de saberes já existentes nos espaços comunitários rurais. A partir disso, pondera-se que as práticas de linguagem do contexto acadêmico diário de comunidades acadêmicas, como as da LEC-UFVJM, devem ser entendidas em um contex to de disputas entre pressupostos da Educação do Campo, por um lado, e um olhar acadêmico hegemônico e já consolidado sobre escrita, ensino, produção científica, por outro.

\footnotetext{
${ }^{5}$ A respeito de visões presentes em discursos públicos sobre letramentos, ver também Barton (1994).
} 
Observa-se, portanto, que debates recentes sobre letramentos também possuem muito a contribuir nesse processo de pensar o curso e, em especial, a área de Linguagens e Códigos. Dentro da realidade da LEC-UFVJM, as discussões sobre letramentos têm se alinhado ao Projeto Nacional de Letramentos: Linguagem, Cultura, Educação e Tecnologia (USP/CNPQ) $)^{6}$ o qual apresenta um diálogo direto com a formação e projetos de ensino, pesquisa e extensão dos professores que compõem o núcleo parceiro da UFVJM. ${ }^{7}$ Coordenado pelos professores Lynn Mário T. Menezes e Walkyria Monte Mór da Universidade de São Paulo desde o ano de 2009, o projeto encontra-se em seu segundo ciclo e conta com a participação de núcleos parceiros, compostos por professores pesquisadores, alunos de pósgraduação e graduação, em diversas regiões do país. O projeto tem como objetivo geral desenvolver estudos e pesquisas voltados à formação inicial e continuada de professores de línguas, focalizando questões culturais, sociais, linguísticas e tecnológicas.

Esse conjunto de percepções e de pressupostos teóricos sobre questões de linguagem na contemporaneidade motivou o núcleo parceiro da UFVJM do referido projeto a fazer uma reflexão sobre o currículo do curso e, principalmente, sobre a matriz curricular da área de línguas, colocando foco em disciplinas tanto de estudos linguísticos quanto de língua estrangeira. A revisão em questão fez parte de um movimento mais amplo, que envolveu todos os docentes do curso, e que resulta no citado PPC a vigorar a partir de julho de 2018. Esse processo, no que se refere à atuação dos docentes vinculados ao Projeto Nacional de Letramentos, aliou percepções empíricas vindas da prática dos docentes no curso com olhares e reflexões teóricas dos estudos de letramentos e da Linguística Aplicada. As transformações em questão foram pensadas a partir da noção freireana de práxis (FREIRE, 2003), em que a prática refaz a curiosidade investigativa que, por sua vez, continuamente, gera reflexões que a transformam e atualizam. Adotou-se, para tanto, a noção de que "a reflexão crítica sobre a prática se torna uma exigência da relação Teoria/Prática”. Fora dessa condição, para o autor, a teoria pode virar "blablablá e a prática, ativismo" (FREIRE, 2003, p. 22).

\footnotetext{
${ }^{6}$ Disponível em: < http://dgp.cnpq.br/dgp/espelhogrupo/1729742743400062>.

${ }^{7} \mathrm{O}$ núcleo parceiro da UFVJM foi formado no segundo semestre de 2009, após a participação de um dos professores da área de Linguagens e Códigos da LEC-UFVJM, o qual atuava em outro curso da instituição naquele momento, no I Seminar Developing New Literacies in Cross-Cultural Contexts, organizado pelos coordenadores do Projeto Nacional na Universidade de São Paulo. No evento, foi feita a proposta aos participantes para a formação de núcleos parceiros em suas instituições com o objetivo de implementar, de forma colaborativa, o Projeto Nacional. Assim, foram formados núcleos parceiros, dentre eles o da UFVJM. Com a criação da LEC-UFVJM em 2013, o foco do núcleo parceiro da UFVJM, formado, majoritariamente, por professores do curso, voltou-se à formação de professores de línguas para atuar no contex to do campo.
} 
Um estudo pormenorizado desse processo de mudança nas áreas de estudos linguísticos e língua inglesa - envolvendo seus pressupostos teóricos e demandas empíricas observadas na prática - está em curso pelo grupo de docentes vinculados ao referido Projeto Nacional de Letramentos, também com o intuito de ser publicado e contribuir para o debate a respeito da política pública de implementação de licenciaturas em Educação do Campo no Brasil. Na próxima seção, traremos apenas alguns exemplos a respeito dessas mudanças, a título de ilustração e como forma de sustentar o argumento central a respeito de benefícios existentes na articulação entre, de um lado, as demandas da habilitação em Linguagens e Códigos das licenciaturas em Educação do Campo e, de outro, reflexões teóricas recentes da área da Linguística Aplicada e dos estudos de letramento.

\section{Na prática e no currículo: propostas de transformação e percursos de atuação na LEC- UFVJM}

Desde seu primeiro projeto pedagógico ${ }^{8}$, o curso de Licenciatura em Educação do Campo da Faculdade Interdisciplinar em Humanidades (FIH) da UFVJM já se mostrava alinhado com inúmeros aspectos tanto da literatura mais ampla sobre Educação do Campo no Brasil, quanto com os objetivos e construções históricas dos movimentos que antecederam sua institucionalização. Em comum, por exemplo, as preocupações dessas diversas esferas tendem a pensar que:

a identidade da escola do campo é definida pela sua vinculação às questões inerentes à sua realidade, ancorando-se na temporalidade e saberes próprios dos estudantes, na memória coletiva que sinaliza futuros, na rede de ciência e tecnologia disponível na sociedade e nos movimentos sociais em defesa de projetos que associem as soluções exigidas por essas questões à qualidade social da vida coletiva do país (RESOLUÇÃO CNE/CEB 1, de 3 de abril de 2002 apud UFVJM, 2018, p. 6-7).

Em convergência com essa perspectiva, explicitamente inserida dentro do PPC do curso, os autores do projeto ressaltam que, no processo educativo previsto em questão, "[a] universidade não deve substituir saberes e sim articulá-los, promovendo movimentos de diálogos que resultam em novas possibilidades de conhecimentos e de práticas” (UFVJM, 2018, p. 39).

${ }^{8} \mathrm{O}$ primeiro projeto pedagógico da LEC-UFVJM foi elaborado em 2012. 
Materializar e operacionalizar essas mudanças, no entanto, não é óbvio. Tal processo envolve tanto a Educação do Campo como área de pensamento que começa a ser construída antes da política pública nacional de uma institucionalização massiva de suas licenciaturas, como também, e até em decorrência desse processo, um conjunto de esperanças, palavras de ordens e práticas educativas trazidas por movimentos sociais e outras instâncias da sociedade - as quais passam a enfrentar certo atrito quando, em sua implementação enquanto política pública, precisam enfrentar uma lógica acadêmica mais ampla, anterior e já bem consolidada nas instituições.

A breve contextualização a que nos propusemos nas seções anteriores busca ajudar a compreender muitos desses desafios ligados à Educação do Campo enquanto área de interesse acadêmico, bem como à implementação e à manutenção dos cursos de graduação que habilitam e certificam educadores do campo formalmente licenciados. Também é possível, a partir disso, compartilhar um pouco da experiência empírica cotidiana de processos, acordos e disputas institucionais para - na prática cotidiana do curso regular da LEC/UFVJM e, em particular, da área de línguas - a efetivação ou não dos anseios desse olhar a respeito da Educação do Campo que tem ganhado espaço no debate público desde antes de sua incorporação pelas universidades.

Relembramos aqui, por exemplo, o fato de nossos estudantes passarem um período superior a três meses por semestre em suas próprias comunidades, no que chamamos Tempo Comunidade (TC), recebendo orientações a distância. Vale ressaltar que o TC é destinado ao desenvolvimento de trabalhos em diálogo com as realidades locais, o que diferencia o curso, em sua própria estrutura, do padrão das demais licenciaturas existentes no contexto brasileiro. Assim, nossa busca é pelo uso do potencial que temos para um diálogo que seja tanto mais próximo dos desafios reais de um educador do campo quanto possível. Ou seja: o foco do nosso trabalho é uma construção textual que dialogue com as comunidades e seus sujeitos, bem como abra espaço para uma leitura de mundo (FREIRE, 2001) com menos fronteiras.

Em consonância com esse cenário, buscamos formar estudantes que construam seus textos, seus sentidos, em diálogo com as práticas interativas do seu entorno, do entorno de suas comunidades e projetando possibilidades de diálogos que ampliem seus horizontes. Para tanto, as unidades curriculares do curso devem ser construídas de modo sensível a essas demandas, ou, caso contrário, elas irão conflitar com a própria ideia de se fazer uma educação do campo dialógica. 
Assim, disciplinas foram reelaboradas em uma perspectiva menos disciplinar e mais dialógica diretamente ligadas a práticas de letramentos dos nossos estudantes e outros atores de suas comunidades. Como exemplos, podemos citar, de início, a mudança ocorrida na área de língua estrangeira. Se antes as disciplinas se organizavam em uma estrutura de progressão linear, comum aos cursos de idiomas - passando do inglês básico até chegar ao avançado, o novo PPC passa a organizar as disciplinas a partir de temas relevantes e contemporâneos, tal como já se pode antever a partir das novas propostas, as quais seriam: Lingua Inglesa e Cidadania Crítica; Lingua Inglesa e Diversidades; Lingua Inglesa, Globalização e Novas Tecnologias; Lingua Inglesa e Questões Socioambientais.

$\mathrm{Na}$ área de estudos linguísticos, seriam ilustrativas dessa situação, entre outras, as alterações pelas quais passaram as antigas disciplinas Metodologia do Ensino de Língua Portuguesa e Ensino de Língua Portuguesa e Novas Tecnologias. A primeira passa a se chamar Educação Linguística e o Ensino de Língua Portuguesa com uma ementa que tem a finalidade de focar uma perspectiva de ensino de uma língua plural e em constante transformação, uma perspectiva de educação linguística de acordo as premissas da LA que, nesse sentido, deve ter uma perspectiva dialógica e, portanto, contextualizada na Educação do Campo. A segunda disciplina citada passar a receber o nome de ensino de Língua Portuguesa e Novas Tecnologias e tem sua carga horária aumentada de 30 para 60 horas. Nota-se, não só pelo aumento de carga horária como pela leitura da ementa, o papel de destaque dado aos letramentos digitais, aos processos individuais de aprendizagem e ao ensino também nesse componente curricular'.

As práticas que corroboraram o desenvolvimento deste PPC são variadas e foram essenciais para a investigação de realidades dos estudantes para a produção de sentidos que resultassem em textos, tanto na modalidade escrita quanto na oral, em gêneros diversos. Como exemplo, podemos citar o estudo sobre cenário educacional brasileiro ao final de 2016 promovido pela disciplina Leitura e Produção de Textos que resultou em dossiê produzido pelos estudantes e publicado em um repositório on-line de recursos educacionais abertos. Outro exemplo foram as reflexões promovidas por meio da escrita de memórias de letramentos por parte dos estudantes que, posteriormente, foram publicadas pela editora UFVJM em livro organizado por professores do curso. Essas memórias, por sua vez, serviram às reflexões dos

\footnotetext{
${ }^{9}$ Ementa da disciplina "Ensino de Língua Portuguesa e Novas Tecnologias": Letramento digital e educação do campo: perspectivas e possibilidades. O ensino de línguas e literatura e as novas mídias na educação básica. Cadeias interativas mediadas tecnologicamente (UFVJM, 2018, p. 94).
} 
estudantes sobre seus processos de letramentos que, nesse sentido, foram materializadas em artigos científicos apresentados em congressos.

Nota-se, a partir dos exemplos, que as mudanças aqui apresentadas na grade curricular do curso tiveram como base tanto um referencial atualizado sobre língua e linguagem como também a própria experiência empírica dos docentes envolvidos no curso. Sendo assim, notase que a práxis, entendendo-a como esse exercício dialógico entre teoria e prática, foi privilegiada nesse processo. Ademais, essas mudanças ocorrem no esforço de se manter a habilitação em Linguagens e Códigos em diálogo com as demandas e os fundamentos mais amplos da Educação do Campo, com os quais, argumentou-se neste trabalho, alinham-se as contribuições vindas das reflexões recentes sobre Linguística Aplicada e sobre estudos do letramento.

\section{Considerações finais}

É grande o desafio de formar um licenciado do campo com criticidade e em diálogo com as demandas e anseios próprios das comunidades rurais envolvidas nesse processo. Em parte, esse desafio emerge do próprio esforço inicial presente nas políticas públicas de implementação e consolidação dos cursos de Licenciatura em Educação do Campo nas universidades federais brasileiras. Dentro das questões a serem enfrentadas nas áreas de língua materna e língua estrangeira, observou-se ainda nesse artigo que muitas questões levantadas são comuns aos debates contemporâneos sobre língua, linguagem e ensino. Desse modo, podem encontrar voz e espaço, em partes, em um aparato teórico já existente e anterior à Educação do Campo e que pode ser resgatado, revisado e atualizado conforme as demandas que a prática dialógica fizer emergir. Entende-se, por exemplo, que uma educação voltada para o protagonismo do estudante e seus processos de aprendizagens, tão distintos entre si, deve ofertar possibilidades que consigam pressupor e lidar com a heterogeneidade e com a dinamicidade dessa atividade enquanto ‘acontecimento’ (SIGNORINI, 1998).

Isso, portanto, vai muito além de se estudar objetos já vistos em demasia ao longo da carreira estudantil, e muitas vezes de forma reducionista e descontextualizada, como as nomenclaturas de classes de palavras, das análises sintáticas em toda sua extensão possível ou do estudo sistemático e repetitivo de verbos nunca, ou quase nunca, utilizados. Essa situação narrada é facilmente observável no contexto escolar formal de modo mais amplo e é uma realidade empiricamente vivenciada por muitos professores. Em conjunto com observações 
empíricas experienciadas a respeito dessa situação, é possível também fundamentar tal pensamento a partir do olhar de Antunes (2003), que defende uma aula de português interativa e funcional, que faça parte, ou no mínimo simule, de práticas reais de uso da língua.

Além disso, na prática rotineira do curso, tendo como base a experiência da LECUFVJM, são evidentes algumas limitações como a falta ou a disponibilidade apenas precária de tecnologias atuais, tão úteis à interação, sobretudo entre sujeitos distantes espacialmente. O problema é percebido na própria universidade e na moradia estudantil, bem como nas comunidades dos estudantes que, como citado anteriormente, ficam cerca de três meses distantes da universidade em suas comunidades, rurais em sua maioria, e, portanto, necessitam da mediação tecnológica para o bom andamento de suas vidas acadêmicas.

Nesse sentido, uma discussão sobre currículos e a materialização de uma revisão curricular não são práticas inovadoras em si, mas apontam para um exercício da crítica e da autonomia, características de uma educação que se pretende progressista e dialógica. Aliás, é de se ressaltar que uma visão dialógica sobre a língua existe até antes dos primeiros escritos de Paulo Freire. Bakhtin (2006), por exemplo, entendia os contextos de forma bastante ampla e no livro O marxismo e a Filosofia da Linguagem, escrito inicialmente em 1929, aponta também para o entendimento de que os enunciados são construídos de modo dialógico, em resposta a questões postas no espaço interativo e demandante de novas interações, nas diversas esferas da atividade humana e como resultado desses contextos específicos. O desdobramento dessa discussão chega à Lei de Diretrizes e Bases (LDB), lei de 1996 que rege a educação brasileira, aos Parâmetros Curriculares Nacionais (PCN), as regulamentações estaduais e municipais sobre educação e, mais recentemente, à Base Nacional Curricular Comum (BNCC).

Desse modo, as reflexões aqui propostas não pretendem encerrar qualquer discussão sobre a consolidação ou manutenção da Licenciatura em Educação do Campo ou, mais particularmente, da habilitação em Linguagens e Códigos. Diferentemente, a busca foi por contribuir com as investigações sobre esse tópico, ainda recente enquanto objeto de estudo acadêmico.

\section{Referências}

ANDRADE, L. A. M. O desafio da parceria na implementação do PRONERA: o caso do Projeto Alfabetização Cidadã no Nordeste Paraense. Dissertação (Mestrado) - Mestrado em Educação. Universidade Federal do Rio Grande do Norte, Natal. 186 f. 2009. 
ANTUNES, I. Aula de português: encontro \& interação. 6. ed. São Paulo: Parábola Editorial, 2003.

BAKHTIN, Mikhail. (VOLOCHINOV). Marxismo e filosofia da linguagem. 12. ed, São Paulo: Hucitec, 2006.

BARTON, D. Literacy: An introduction to the ecology of written language. Oxford: Blackwell, 1994.

BOURDIEU, P. A economia das trocas linguísticas. São Paulo: Edusp, 1996.

BRASIL. Edital de Seleção no. 02/2012 - SESU/SETEC/SECADI/MEC de 31 de agosto de 2012.

$<\mathrm{http}$ // portal.mec.gov.br/index.php?option=com_docman\&view=download\&alias=13300edital-02-2012-sesu-setec-secadi-3 1-agosto-20 12-pdf\&category_slug=junho-2013pdf\&Itemid=30192> . Acesso em: 28 mar. 2018.

BRASIL. Lei n ${ }^{\circ}$ 9.394, de 20 de dezembro de 1996. Estabelece as diretrizes e bases da educação nacional. Brasília, 1996. Disponível em: < http://www.planalto.gov.br/ccivil_03/Leis/L9394.htm >. Acesso: 28 mar. 2018.

BRASIL. Secretaria de Educação Fundamental. Parâmetros curriculares nacionais : terceiro e quarto ciclos do ensino fundamental: introdução aos parâmetros curriculares nacionais / Secretaria de Educação Fundamental. Brasília : MEC/SEF, 1998. Disponível $\mathrm{em}:<$ http://portal.mec.gov.br/seb/arquivos/pdf/introducao.pdf $>$. Acesso em: 28 mar. 2018.

BRASIL. Base Nacional Comum Curricular. Brasília: MEC, 2016. Disponível em: < http://basenacionalcomum.mec.gov.br/wp-content/uploads/2018/02/bncc-20dezsite.pdf>. Acesso em: 28 mar. 2018.

EVENSEN, L. S. A Lingüística Aplicada a partir de um arcabouço com princípios caracterizadores de disciplinas e transdisciplinas. In: SIGNORINI, I.; CAVALCANTI, M. C. (Org.) Lingǘstica Aplicada e Transdisciplinaridade. Campinas: Mercado das Letras, 1998, p. 8198.

FABRÍCIO, B. F. Linguística Aplicada como espaço de desaprendizagem: redescrições em curso. In: MOITA LOPES, L.P. da. Por uma Linguística Aplicada Indisciplinar. São Paulo: Parábola, 2006, p. 15-66.

FREIRE, P. A importância do ato de ler em três artigos que se completam. 41. ed. São Paulo: Cortez, 2001.

FREIRE, P. Pedagogia da Autonomia: saberes necessários à prática educativa. $28^{\mathrm{a}} \mathrm{ed}$. São Paulo: Paz e Terra, 2003.

LIMA, A. V. Educação do Campo e Pedagogia da Alternância: algumas considerações metodológicas. Entrelaçando, Cruz das Almas, UFRB, v. 2, n.7, ano III, p. 46-60, 2012.

MOITA LOPES, L. P. da. (Org). Por uma Linguística Aplicada Indisciplinar. São Paulo: Parábola, 2006. 
MOITA LOPES, L. P. da. (Org).Da aplicação de Linguística à Linguística Aplicada Indisciplinar. In: PEREIRA, R. C. M; ROCA, M. P. (Org.). Linguística Aplicada: um caminho com diferentes acessos. São Paulo: Contexto, 2009, p.11-24.

MOLINA, M. C.; ANTUNES-ROCHA, M. I. Educação do Campo: história, práticas e desafios no âmbito das políticas de formação de educadores - reflexões sobre o PRONERA e o PROCAMPO. Revista Reflexão e Ação, Santa Cruz do Sul, v.22, n.2, p.220-253, jul./dez.2014. Disponível em: <https://online.unisc.br/seer/index.php/reflex/article/view/5252 >. Acesso em: 23 abr. 2018.

RIBEIRO, M. Educação Rural. In: CALDART, R.S; PEREIRA, I.B; ALENTEJANO, P; FRIGOTO, G. (Orgs). Dicionário de Educação do Campo. Rio de Janeiro, São Paulo: Escola Politécnica de Saúde Joaquim Venâncio, Expressão Popular, 2012.

SANTOS, B. S.; MENEZES, M. P.; NUNES, J. A. Para ampliar o cânone da ciência: a diversidade epistemológica do mundo. In: SANTOS, B. S. (Org.). Semear outras soluções. Rio de Janeiro: Civilização Brasileira, 2005, p. 21-122.

SEMINÁRIO NACIONAL POR UMA EDUCAÇÃO DO CAMPO. Declaração - 2002. In: KOLLING, E. J.; CERIOLLI, P. R.; CALDART, R; S. (Org.). Educação do Campo: identidade e políticas públicas. Brasília, DF: articulação nacional Por Uma Educação do Campo, 2002. Coleção Por Uma Educação do Campo, no. 4. Disponível em: < http://www.forumeja.org.br/ec/files/Vol\%204\%20Educa\%C3\%A7\%C3\%A30\%20B\%C3\%A 1 sica\%20do\%20Campo.pdf>. Acesso em: 26 abr. 2018.

SIGNORINI, I. Do residual ao múltiplo e ao complexo: o objeto da pesquisa em Lingüística Aplicada. In: SIGNORINI, I.; CAVALCANTI, M. C. (Org.). Lingüística Aplicada e Transdisciplinaridade. Campinas: Mercado das Letras, 1998, p. 99-1 10.

STREET, B. V. Letramentos Sociais: abordagens críticas do letramento no desenvolvimento, na etnografia e na educação. Trad. Marcos Bagno. São Paulo: Parábola Editorial, 2014.

UNIVERSIDADE FEDERAL DOS VALES DO JEQUITINHONHA E MUCURI UFVJM. Projeto Pedagógico de Curso da Licenciatura em Educação do Campo. Diamantina, MG, 2014.

2018

Projeto Pedagógico de Curso da Licenciatura em Educação do Campo. Diamantina, MG, 